\title{
An Update on Chronic Hepatitis
}

\author{
R.N.M. MACSWEEN, FRCS, FRCPath \\ University Department of Pathology, Western Infirmary, University ofGlasgow \\ Glasgow, Scotland, United Kingdom
}

\begin{abstract}
Chronic hepatitis has been broadly defined as liver inflammation without improvement for at least 6 months. A more accurate definition is Hit is a chronic necroinflammatory disease of variable severity that is not associated with features of chronic cholestasis or with steatasis or Malory body formation." Histological classification of chronic hepatitis included chronic persistent hepatitis. chronic active hepatitis, and chronic lobular hepatitis. The histopathological aspects of chronic hepatitis are discussed.
\end{abstract}

Keywords: Chronic hepatitis, Classification, Liver disease.

\section{Introduction}

Chronic hepatitis has been broadly defined as inflammation of the liver continuing without improvement for at least six months! 1 A better focused definition would be that "Chronic hepatitis is a persistent necroinflammatory lesion primarily affecting hepatocytes, in which there is a predominantly lymphocytic infiltrate and which, in many cases, results in cirrhosis.". However, a more extended and more accurate definition would be as follows: "Chronic hepatitis is a chronic necroinflammatory disease of variable severity that is not associated with features of chronic cholestasis or with steatosis or Mallory body formation. It is generally a progressive disease, but the evolution to end-stage liver disease depends on the aetiology." This definition excludes chronic, cholestatic liver disease and alcoholic liver disease, both of which are forms of chronic hepatitis and which may progress to cirrhosis. In addition, this definition, while indicating the progressive nature of the disease, indicates that the evolution of cirrhosis is dependent on the aetiology. To this one might add that the evolution may also be modified by therapeutic measures such as immunosuppression and anti-viral agents.

Correspondence \& reprint requests to: Prof. R.N.M. MacSween, University Department of Pathology, Western Infirmary, Glasgow Gil 6NT, Scotland, U.K. (Presented at the International Symposium on Pathology and Laboratory Medicine. J5-17 November J997, Jeddah, Saudi Arabia.) Accepted for publication: 16 March J998. Received: 27 October 1997 
The earliest histological classification of chronic hepatitis was that by De Groote et al[2l. In this paper (which became a citation classic) chronic hepatitis was subdivided into chronic persistent hepatitis which was thought to carry a good prognosis, and chronic active (aggressive) hepatitis in which the prognosis was poorer and the end result, in most patients, was cirrhosis. This classification was essentially a grading system indicating a spectrum of activity from the relatively benign pattern, chronic persistent hepatitis, through chronic active hepatitis which could be of varying severity but which could progress to cirrhosis. A further type, chronic lobular hepatitis, was added in 1971 [3].

De Groote $e a^{\prime}$ 's classification was used for many years but, with the discovery of a number of hepatitis viruses and recognition of the fact that so-called piecemeal necrosis, the hallmark of chronic active hepatitis, could occur in a widerange of liver diseases, the utility of the classification was called into question[4,5]. Furthermore, the morphological classification was transferred into the clinical setting creating the erroneous impression that chronic persistent and chronic active hepatitis were disease entities. It also became clear that in response to immunosuppression, the histological features of chronic active hepatitis could resolve and biopsies to monitor response to treatment would show the appearance of chronic persistent hepatitis. The discovery of hepatitis $\mathrm{C}$ in particular, and recognition of the fact that following acute infection some $70 \%$ of patients pursued a chronic course, determined the need to introduce a new classificationlvl, This new classification is now on an aetiological basis and is summarised in Table 1.

TABLE 1. An aetioiogical classification of chronic hepatitis.

\begin{tabular}{|l|l|}
\hline Chronic viral hepatitis & $\begin{array}{l}\text { HBV with or without HDY } \\
\text { Hey }\end{array}$ \\
\hline Chronic autoimmune hepatitis & $\begin{array}{l}\text { type I (ANA autoantibody) } \\
\text { type II (LKMl-autoantibody) } \\
\text { type III (SLAILP autoantibody) }\end{array}$ \\
\hline Chronic drug-induced hepatitis & (may be associated with autoantibodies) \\
\hline Chronic cryptogenic hepatitis & \\
\hline
\end{tabular}

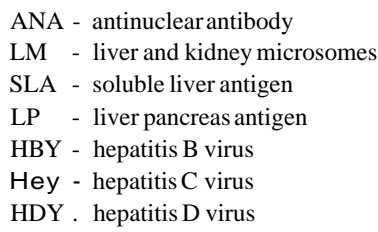

Histological aspects of chronic hepatitis: The diagnosis of chronic hepatitis is made on the basis of the clinical, biochemical, and serological (viral antibodies and autoantibody profile) findings. The indications for liver biopsy are to verify the diagnosis, to confirm the aetiology (in particular in the case of chronic HBV where the expression of surface and core antigens can be assessed), to assess the grade and stage of the disease, to monitor and evaluate the effect of therapy, and to carry out any special or investigative studies. 
The histological features of chronic hepatitis comprise a combination of an inflammatory cell infiltrate, accompanied by liver cell injury and necrosis. The inflammatory infiltrates involve both the portal tracts and the acini (lobules). In addition, there is often periportal inflammation (and in later stages periseptal inflammation) and for this the term "interface hepatitis" is now used in preference to piecemeal necrosis. Interface hepatitis, therefore, comprises hepatocyte necrosis at an interface between parenchyma and the connective tissue of portal tracts or fibrous septa, and this is accompanied by a predominantly lymphocytic infiltrate with various numbers of plasma cells, antigenpresenting cells and macrophages. Within the acini, hepatocytes show swelling and degeneration, acidophil change (apoptosis) and, in addition, undergo lytic necrosis of single cells or groups of cells (spotty necrosis).

When there is widespread necrosis of adjacent hepatocytes, this constitutes confluent necrosis and this is seen mainly in the periveenular area (acinar zone 3 ). With more severe injury, areas of confluent necrosis may effect links/connections between vascular structure, in particular hepatic veins and portal tracts. This is called "bridging necrosis" and may be central-central bridging (hepatic vein to hepatic vein) or portal-central bridging (portal tracts to hepatic veins). Of these two types of bridging, necrosis portalcentral represents a more severe form of injury in that it causes a greater disturbance of the liver architecture and, correspondingly, its presence may indicate a poorer clinical prognosis. Where there is even more severe injury with extensive confluent necrosis, then areas of massive necrosis are seen and this may involve entire acini.

In reporting liver biopsies in chronic hepatitis, it is now recommended that particular attention should be paid to four of the morphological components, namely the portal tract inflammation, periportal interface hepatitis, intra-acinar or intralobular activity and the presence of confluent necrosis. These components of the chronic hepatitis can be variously graded; and a number of grading systems have been recently recommended in order to try and quantify or score and derive a histological activity index--HAI[4,9-10J (see Tables 2-4). The limitations of semi-quantitative score systems in histopathology have to be borne in mind[II-12]. These limitations include the fact that the assessment is very much a subjective one and it is important to 'have clear-cut definitions of the features which are to be assessed. There may be focal variation in the degrees of activity as between one part of the biopsy and the other, and variation may arise because of the size and adequacy of the biopsy. Where the use of the more elaborate grading systems may be indicated in extended clinical trials, simpler systems may be entirely appropriate to the routine reporting of liver biopsies. In the simplest system and for centres involved with only a small number of cases, it is enough to assess the activity as being minimal, mild, moderately severe, or severe. It is worth noting that at the minimal end of the spectrum, the changes may resemble those seen in patients with what is otherwise virtually normal liver histology!14-15].

In addition to assessing the degree of activity in a biopsy, it is also useful to stage the disease. In this assessment the presence of fibrosis and the degree of architectural disturbance are important, cirrhosis!s5] representing the most advanced, and an irreversible stage, of the Iiver injury (see Table 5). 
ABI.1: 2. Assessment of histological activity index (HA1) (after Knodell et $a l^{|8|}$ ).

\begin{tabular}{|l|c|}
\hline \multirow{2}{*}{ Periportal inflammation \pm bridging necrosis } & Range of Scores \\
\cline { 2 - 2 } & $0-10$ \\
\hline Intralobular hepatocyte degeneration and focal necrosis & $0-4$ \\
\hline Portal inflammation & $0-4$ \\
\hline Fibrosis & $0-4$ \\
\hline & 22 \\
\hline
\end{tabular}

TABU: 3. Assessment of histological activity index (HAl) (after Ishak et al ${ }^{(9)}$ ).

\begin{tabular}{|l|c|}
\hline \multirow{2}{*}{$\begin{array}{c}\text { Portal inflammation } \\
\text { Absent through to marked (all portal tracts intensely inflamed) }\end{array}$} & Range of Scores \\
\cline { 2 - 2 } & $0-4$ \\
\hline $\begin{array}{l}\text { Periportal/periseptal (interface) hepatitis } \\
\text { Absent through to severe (continuous in }>50 \% \text { of portal tracts or septa) }\end{array}$ & $0-4$ \\
\hline $\begin{array}{l}\text { Confluent necrosis } \\
\text { Absent through to pan-acinar necrosis }\end{array}$ & $0-6$ \\
\hline $\begin{array}{c}\text { Focal spotty necrosis, apoptosis and focal inflammation } \\
\text { Absent through .to }>\text { ten foci per x 10objective }\end{array}$ & $0-4$ \\
\hline \multicolumn{1}{|c|}{ Maximum score } & 18 \\
\hline
\end{tabular}

TABLE 4. Assessment of histological activity index (after Scheuer ${ }^{[3.3]}$ ).

\begin{tabular}{|c|c|}
\hline \multirow{2}{*}{$\begin{array}{c}\text { Portal and pen portal activity } \\
\text { Absent through to severe/interface hepatitis }\end{array}$} & Range of Scores \\
\cline { 2 - 2 } & $0-4$ \\
\hline $\begin{array}{c}\text { Lobular (intra-acinar) activity } \\
\text { Absent through to severe hepatocyte damage including bridging necrosis }\end{array}$ & $0-4$ \\
\hline Maximum score & 8 \\
\hline
\end{tabular}

TABı. 5. Assessment of stage based on architectural changes, fibrosis and cirrhosis (after Ishak et al ${ }^{[9]}$ ).

\begin{tabular}{|l|c|}
\hline & Score \\
\cline { 2 - 2 } & $\mathrm{I}$ \\
\hline Fibrous expansion of some portal areas. \pm short fibrous septa & 2 \\
\hline Fibrous expansion of most portal areas with occasional portal to portal (P-P) bridging & 3 \\
\hline Fibrous expansion of portal areas with marked bridging (P-P) as well as portal to central (P-C) & 4 \\
\hline Marked bridging (P-P and/or P-C) with nodules (incomplete cirrhosis) & 5 \\
\hline Cirrhosis, probable or definite & 6 \\
\hline Maximum score & 6 \\
\hline
\end{tabular}


In addition to assessing the degree of activity in a biopsy, it is also useful to stage the disease. In this assessment the presence of fibrosis and the degree of architectural disturbance are important, cirrhosis! 15] representing the most advanced, and an irreversible stage, of the liver injury (see Table 5).

\section{References}

[1] Fogarty International Center Criteria Committee. Diseases of the liver and biliary tract. Standardization of nomenclature, diagnostic criteria. and diagnostic methodology. Washington: U.S. Government Printing Office 1976: 9-11.

(2) De Groote J, Desmet V, Gedigk P, Korb G, Popper H, Poulsen H, Scheuer PJ, Schmid M, Thaler H, Uehlinger F, Wepler W. A classification of chronic hepatitis. Lancer 1968: ii: 626-628.

[3] Popper H, Schaffner F. The vocabulary of chronic hepatitis. N Engl J Med 1971:284:1 154-1 J56

[4] Scheuer PJ. Classification of chronic viral hepatitis: a need for reassessment. J Hepatol 1991: 13: 371-374.

[5] Ludwig J. The nomenclature of chronic active hepatitis: an obituary. Gastroenterology 1993: 105: 274-278.

[6] Zuckerman A, Thomas HC. Viral Hepatitis. Churchill Livingstone, 1997,56-59.

[7] Desmet VJ, Gerber M, Hoofnagle JH, Manns M, Scheuer PJ. Classification of chronic hepatitis: diagnosis, grading and staging. Hepatology 1994; 19: 1513-1520.

[8] Knodell RG, Ishak KG, Black WC, Chen TS, Craig R, Kaplowitz N, Kiernan TW, Wollman J. Formulation and application of a numerical scoring system for assessing histological activity in asyrnptomatic chronic active hepatitis. Hepatology 1981: 1(5): 431-435.

[9] Ishak K, Baptista A, Bianchi L, Callea F, De Groote J, Gudat F, Denk H, Desmet V, Korb G, MacSween RN. Histological grading and staging of chronic hepatitis. J Hepatol 1995: 22(6): 696-699.

[10] Bedossa P, Poynard T. An algorithm for the grading of activity in chronic hepatitis. The METAVIR Cooperative Study Group. Hepatology 1996: 24(2): 289-293.

[I I] The French MET AVIR Cooperative Study Group. Intraobserver and interobserver variations in liver biopsy interpretation in patients with chronic hepatitis C. Hepatology 1994: 20: 15-20.

[12] Goldin RD, Goldin JG, Burt AD, Dhillon PA, Hubscher S, Wyatt J, Patel N. Intra-observer and inter-observer variation in the histopathological assessment of chronic viral hepatitis. J Hepatol 1996; 25 (5): 649-654

[13] Scheuer PJ. Chronic hepatitis: what is activity and how should it be assessed? Histopatholog.' 1997: 30: $103-105$.

[14] Kay EW, O'Dowd J, Thomas R. Mild abnormalities in liver histology associated with chronic hepatitis: distinction from normal liver histology. J Clin Pathol 1997: 50: 929-931.

[15] Poynard T, Bedossa P, Opolon P. Natural history of liver fibrosis progression in patients with chronic hepatitis C. Lancet 1997: 349: 825-832. 


$$
\text { تحــديث عن الالتهــاب الكبــدي المــزمن }
$$

\footnotetext{
ر•ن ماكسوين

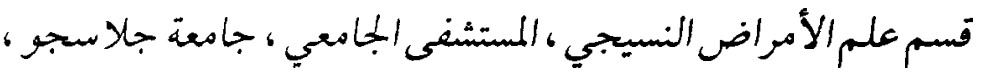

جلاسجو ، اسكتلندا
}

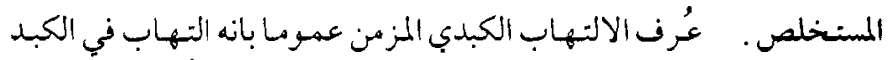

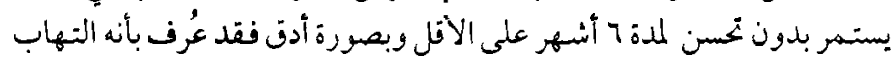

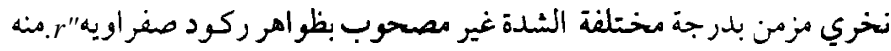

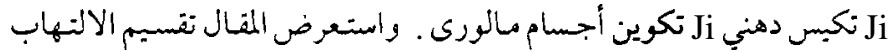

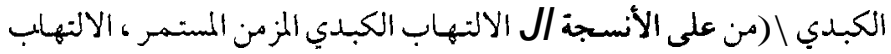

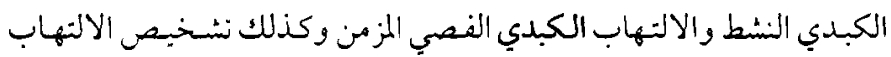

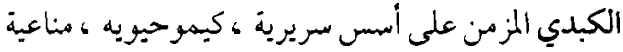

